\title{
Environments and System Types of Virtual Reality Technology in STEM: A Survey
}

\author{
Asmaa Saeed Alqahtani \\ Department of Computer Science \\ Najran University \\ Najran, Saudi Arabia
}

\author{
Dr. Lamya Foaud Daghestani \\ Department of Computer Science \\ King Abdulaziz University \\ Jeddah, Saudi Arabia
}

\author{
Prof. Lamiaa Fattouh Ibrahim \\ Department of Computer Science \\ King Abdulaziz University \\ Jeddah, Saudi Arabia
}

\begin{abstract}
Virtual Reality (VR) technology has been used widely today in Science, Technology, Engineering and Mathematics (STEM) fields. The VR is emerging computer interface distinguished by high degrees of immersion, trustworthy, and interaction. The goal of VR is making the user believe, as much as possible, that he is within the computergenerated environment. The VR has become one of the important technologies to be discussed regarding its applications, usage, and its different types that can achieve huge benefits in the real world. This survey paper introduces detail information about VR systems and requirements to build correct VR environment. Moreover, this work presents a comparison between system types of VR. Then, it presents the tools and software used for building VR environments. After that, we epitomize a road of the map for selecting appropriate VR system according to the field of applications. Finally, we introduce the conclusion and future predictions to develop the VR systems.
\end{abstract}

Keywords-Virtual reality; $3 D$ graphics; immersion; $3 D$ images; navigation; multimedia

\section{INTRODUCTION}

In most of the sciences which contained concepts and principles of 3D images, there is a need to represent it using the technology of VR. The VR is a natural extension to $3 \mathrm{D}$ computer graphics consisted of 3D manufacturing and design tools to create and design computer-aided engineering [1], [2].

The VR has become one of the important technologies to be discussed regarding its applications, usage, and its different types that can achieve huge benefits in the real world. The VR considered as full visualization environment using appropriate computer technologies. In most of the learning environment, the VR becomes possible for many learners or trainees to simulate the real world. The benefits of this technology often start with computer graphics and continue for long times.

The VR allows the user and learner to watch the external world by different dimensions as its real world in and to try things that are not accessible in real life or even not yet created [3]. Also, it could be said that the VR depends on the internet networks and simulation that can help trainers or educators to interact through motion, embodiment and graphical images that idealize persons. So, VR can be defined in general as computer graphics that allowing to see the unseen and provides new shrewdness into the underlying data [4].

Many years ago, educators started to explore VR as a powerful multimedia for the education. The VR allows for continuing and growing social interaction that can enhance cooperative learning. VR can adapt and grow to meet different user needs.

The next section discusses concepts of VR. Section 3 represents the emergence of VR till date. After that Section 4 discusses VR applications, then Section 5, VR requirements. Section 6 discusses essential elements of VR environments. Section 7 talks about the literature review. Section 8 discusses the VR software and tools. Section 9 shows the navigation in VR environments. Section 10 represents benefits and limitation of VR technology. Section 11 summarizes the road map of this survey. The paper's conclusion is presented in Section 12.

\section{CONCEPTS OF VIRTUAL REALITY}

The use of $3 \mathrm{D}$ as it is a virtual world in education is to increase because the $3 \mathrm{D}$ virtual world has a strong sense of existence even in remote participants, and because it increases the social awareness and communication of human [5].

Many researchers have previously talked about the term of VR. In this section, we will highlight some of the most prominent and important definitions concerning the term VR.

The VR is emerging computer interface distinguished by high degrees of immersion, trustworthy, and interaction. The goal of VR is making the user believe, as much as possible, that he is within the computer-generated environment [6].

According to [7], the VR is "technology that allows us to create environments where we can interact with any object in real time, and that has been widely used for training and learning purposes." The integration some of technologies and hardware such as computers and graphics software can generate the technology of VR. So, the VR can be summed up as it is a progressing computer interface to allow the user to be immersed in a simulated environment generated by a computer.

Over and above, the VR can be defined as it is a system according to [2], which said that the VR is "human-computer environments in which users are immersed in and able to perceive, act and interact with a three-dimensional world." The VR has no criterion definition that makes it considered as a difficult task. VR can be an oxymoron as it denoted by some school of intellect as "reality that does not exist" [8]. There are many names used interchangeably with the VR. These names can be Virtual Environment, Artificial Reality, Virtual Worlds, Artificial Worlds, or Cyberspace. 
The Virtual Environment (VE) defined as a digital space in which a user's movement is tracked and his or her surroundings playback, or numerals composed and offered to the senses, by those movements. For instance, when educators start using computer playtimes it can be noticed that handlebar movement can be followed and tracked and his or her character moves forward, rendering a new environment [9].

\section{EMERGENCE OF VR TECHNOLOGY}

The term VR came from Jaron Lanier, who is the founder of VPL Research. However, it was in 1965 that Ivan Sutherland published a paper entitled "The Ultimate Display" which described how one day; the computer would provide a window into virtual worlds [3].

VR came into public consciousness as a medical toy with equipment's including kid's MX Motocross, helmet, glove, and others which were discriminatory determined from the wider public and the price of this system will not be expensive. After that the companies, which produce the system of VR, directed to develop and provide the system for the data collected and analyzing it. This usage could be indicated that the VR often used in the application that is based on 3D space for analyzing and in the visualization of overall physical dimensions. The data used in VR substantially integrated due to the ability of VR to display 3D data with sounds and touch information [10].

The emergence of VR can be highlighted at the following main points [3]:

\section{A. Sensorama (invited in 1957, Morton Heilig)}

Sensorama is a machine patented in 1962. The system of Sencorama consisted of multi sensors that could make a chromatic film that previously recorded to be augmented by clear sound, smell, the wind and related vibration. The Sensorama was the first way to explore the system of VR. It had most of the features of such environment, but without interaction [11]. Fig. 1 shows the Sensorama machine. The Sensorama allow people to enter in the style of an interactive cinema [12].

\section{B. The Ultimate Display (invented in 1965, Ivan Sutherland)}

Sutherland tried to suggest a definitive solution for the VR. The suggestion aimed to make system consists of interactive graphics, with sound, smell, and force feedback as the construction of an artificial world. Fig. 2 shows the proposed ultimate display.

The ultimate display suggests using like a Head Mounted Display (HMD) to be as a window for the VR [13]. Sutherland said in his words about the ultimate display, it as "room within which the computer can control the existence of matter. A chair displayed in such a room would be good enough to sit in. Handcuffs displayed in such a room would be confining, and a bullet displayed in such a room would be fatal." [12], [14].

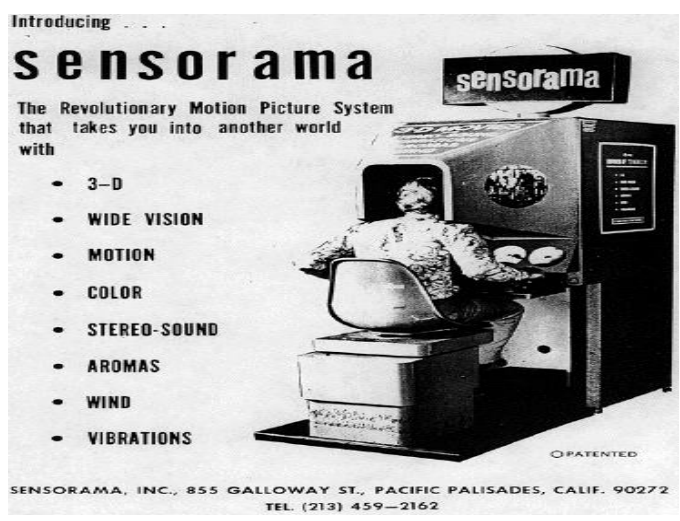

Fig. 1. Sensorama simulator device, [15].

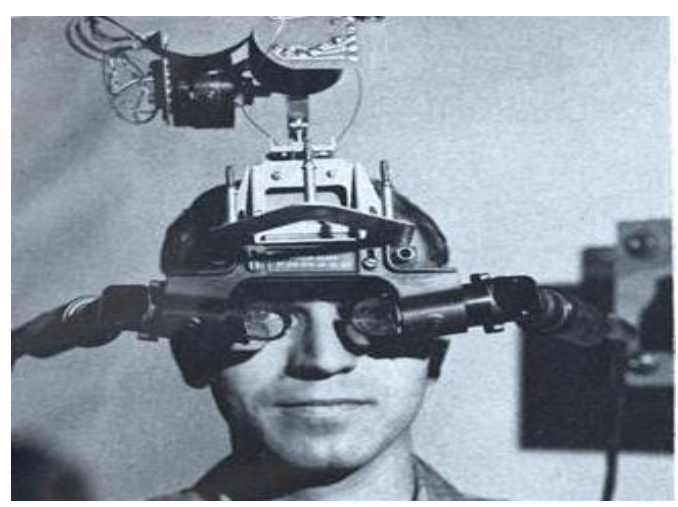

Fig. 2. The ultimate display, [16].

\section{The Sword of Damocles}

The Sword of Damocles is neither system nor the early concept of the VR. It considered as the first hardware of VR. The first Head Mounted Display (HMD) constructed by Sutherland. It contains sounds as stereo updated due to the position and navigation of the user. It is the implementation of the ultimate display.

\section{GROPE}

GROPE is "The first prototype of a force-feedback system realized at the University of North Carolina (UNC) in 1971". According to the notion of Sutherland's system, the UNC developed a system to force feedback devices and allow users feel simulated computer force [17], [11]. Fig. 3 shows the example of a force feedback device. It consists of a simple glove with a specific structure to give sensible feedback with "mechanically complex exoskeletal hand masters" [11].

GROPE aimed to combine both haptic display and visual one to produce a GROPE system. The latest prototype of GROPE is shown in Fig 4. It consisted of "ceiling-mounted arm coupled with a computer and was used by the chemists for a drug-enzyme docking procedure" [11]. 


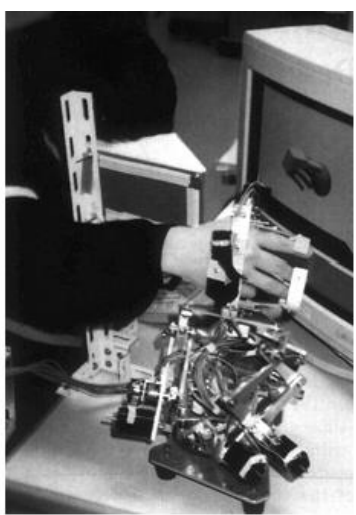

(a)

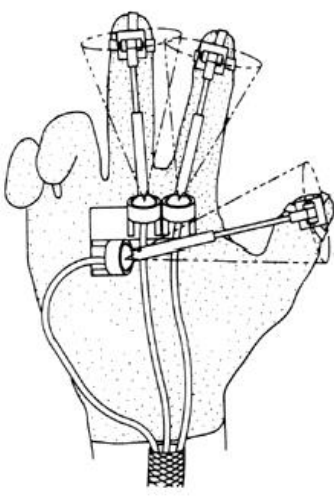

(b)
Fig. 3. Force feedback hand masters: (a) Master Manipulator, (b) force feedback structure for the data glove), [11].

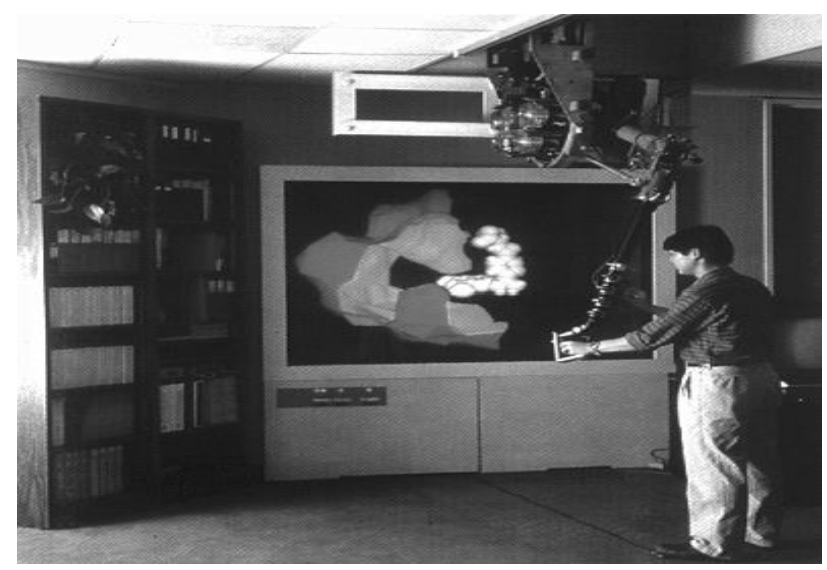

Fig. 4. GROPE force feedback display, [11], [16].

\section{E. VIDEOPLACE (invented in 1975, by Myron Krueger)}

It is "a conceptual environment, with no existence." The VIDEOPLACE artificially created to allow the computer device to control the relationship, the images of users and the places in the scene of the graphic. The imagination shadow of users in VIDEOPLACE system is determined by the camera that posted on a screen. The user in this system can interact with other participants objects [11].

Fig. 5 shows the concept and components of video place. It consists of two rooms next to each other and in any place, camera captures the gesture of participants, a projection screen to control and monitor the movements of users. The images of users are seen by other participants in the second room. Each of the participants in both rooms can interact with the images of each other. The user can interact with images of himself, can zoom it, move it, rotate it, and shrunk it. The user also can interact with graphically represented [18].

\section{F. VCASS (developed in 1982, Thomas Furness)}

Furness developed the "Visually Coupled Airborne Systems Simulator." It is a sophisticated flight simulator. The graphics are describing targeting used in this system by a fighter pilot who wears a Head Mounted Display (HMD [19]).

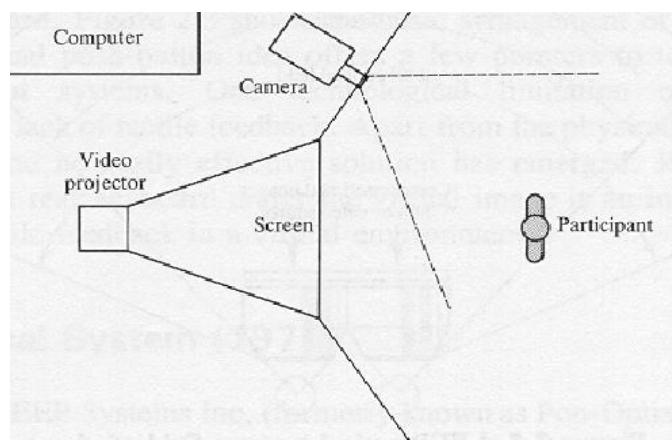

Fig. 5. Video place, [16].

\section{G. VIVED (created in 1984)}

VIVED is an abbreviation of "Virtual Visual Environment Display" that created at NASA Ames with a stereoscopic monochrome HMD. VIVED was created to allow a person to describe his digital world for other people and see it as 3D space [19]. Fig. 6 shows an example of VIVED.

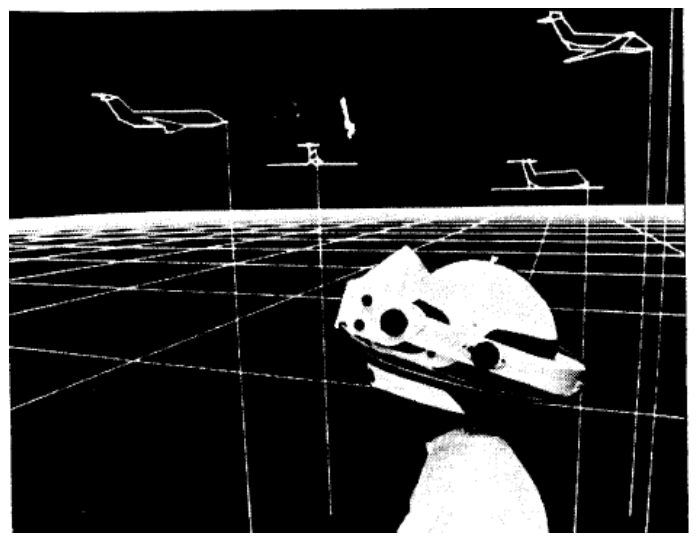

Fig. 6. VIVED, [19].

\section{H. VPL (DataGlove created in 1985 and the Eyephone HMD created in 1988)}

VLP is a company who manufactures and created DataGlove and Eyephone HMD as the first commercially available hardware of VR for the public. The DataGlove was used as an input device. The Eyephone is a head mounted display unit and used to give the user the feeling of immersion [20].

\section{BOOM (created in 1989, Fake Space Labs)}

Binocular Omni-Orientation Monitor (BOOM) is "a small box containing two CRT monitors that can be viewed through the eye holes." In the system of BOOM, the user can take the small box with his/her eye movements, move it through virtual environments and keep track of the box by the eye orientation [17]. Fig. 7 shows the BOOM machine.

\section{J. UNC walk-through project (created in 1980)}

This project was proposed at the University of North Carolina. Many of VR hardware are built to enhance the quality of the UNC Walk-through system such as, "HMDs, optical trackers and the Pixel-Plane graphics engine" [10]. 


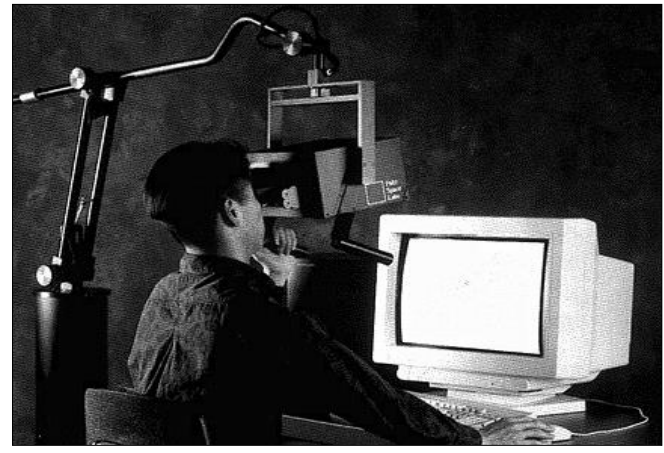

Fig. 7. The Binocular Omni-Orientation Monitor (BOOM), image by [17].

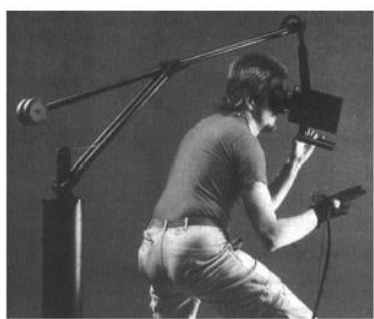

(a)

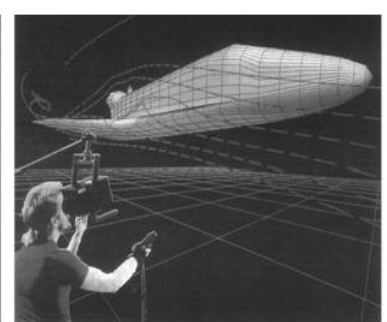

(b)
Fig. 8. Example for the Exploration of airflow using Virtual Wind Tunnel developed at NASA Ames: (a) outside view, (b) inside view [10], [11].

\section{K. Virtual Wind Tunnel (created in 1990)}

Virtual Wind Tunnel developed to allow the monitoring and investigation of flow fields included with BOOM and DataGlove. The Virtual Wind Tunnel is developed at NASA Ames [3]. Fig. 8 shows an example of the Virtual Wind Tunnel. This type of VR helps scientists to utilize a DataGlove to input and manipulate "the streams of virtual smoke in the airflow around a digital model of an airplane or space shuttle. Moving around (using a BOOM display technology) they can watch and analyze the dynamic behavior of air flow and easily find the areas of instability" [10].

\section{CAVE (invented in 1992)}

CAVE is "a VR and scientific visualization system." It uses stereoscopic pictures on the walls of the room instead of using HMD. In CAVE system, the user has to wear LCD shutter glasses "active shutter glasses" [14]. Fig. 9 shows the general structure of the CAVE. It consists of three walls and one door as the fourth wall "flat screens" with projectors to form four projection surfaces. In the CAVE "projection on all six surfaces of a room allows users to turn around and look in all directions. This allows the user to interact with a virtual environment in ways with a better sense of full immersion." [17].

\section{APPLICATIONS OF VR}

Recently, the improvement of software and hardware of computer leads to develop and improve the VR technology and its applications. It has often been used by all the sides and fields of our daily life. Nowadays the user of VR technology is being used in most fields such as education, engineering fields, architectural design, medical practice, games, aerospace, different sports, warlike simulation and many other areas [21].

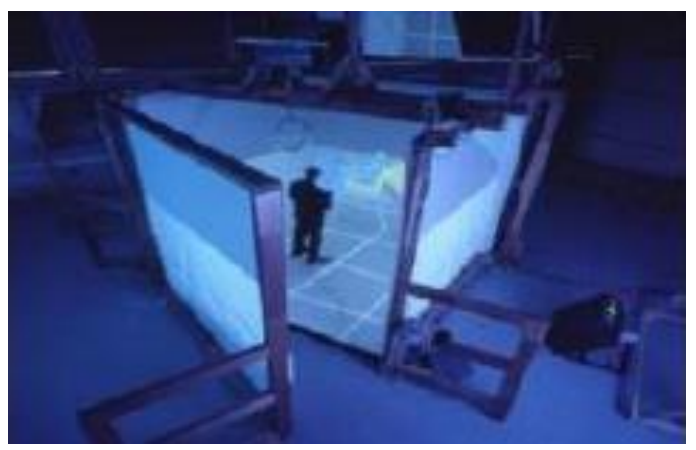

Fig. 9. Cave Automatic Virtual Environment (CAVE), [17].

The VR applications can be summarized as the following:

\section{A. Medicine}

One of the most important and practical uses of VR technique is that it can be used in the field of medicine for a variety of tasks including computational neuroscience, molecular modeling, treating phobias, ultrasound echography, and others. The using of VR will certainly achieve a saving in both cost and time in a practical way in the process of both teaching and training. Another medical application area include VR training simulations that can be used to develop surgeons surgical skills, the main advantage being that no harm will come to animals or human being [22].

\section{Education and Training}

The VR has long been used for education, training and various simulators have been developed for all types of tasks such as planes operation, submarines, power plants, tanks, helicopters, ships, cranes, trains, surgery, cars and air traffic control [23].

\section{Entertainment and Sport}

It can also be said that VR can be applied in the field of sport, for instance, a round of golf can be played using large projection screens in which golf player must direct his ball towards a virtual green. Moreover, a bicyclist can also use VR systems to improve their visual experience when using cycling machines by using large projection screens that update the display according to the speed of that bicyclist. TV cartoons are starting to make use of real-time VR, for example, the BBC's Ratz the Cat, from a children's television program, is animated in real-time during a live broadcast using a tracking system on the puppeteer [21], [22].

\section{B. Engineering and Architecture}

One of the most important usage for VR is the field of engineering. In other words, descriptions of engineering components can be viewed as lifeless drawings or static perspective projections, some of which were animated along a set path through a 3D model. Researcher in [22] indicated that the application of VR had enabled components to be virtually made, examined, gathered and tested with low cost and low time-consuming prototype production. For instance, architects can use VR to take themselves, or their clients, for a walk through the rooms or buildings they are designing. This allows the architect and client to get a real feel for the design and 
allows for possible design changes to be visualized. The advantage of using VR for walk-through instead of CG animations is that the viewer is not restricted to a set path; they can explore the virtual design freely [23].

\section{Data Visualization}

Data visualization is the use of graphical representations of information to make certain characteristics or values more apparent. The Data visualization is especially the case for visualizing complex 3D data sets such as those arising from Computational Fluid Dynamics (CFD) calculations. Data is usually visualized by mapping geometric objects, such as arrows or particle clouds, to the data values. For example, to visualize air flow, arrows could be mapped to the data values where their width could represent volumetric flow rate, color represents temperature and direction represent the direction of air flow [22], [24].

\section{Augmented Reality}

Augmented Reality (AR) "is an upgrade of VR where synthetic stimuli (computer- generated visual, audio or haptic information) are superimposed onto real-world stimuli. [24]" Using this application allows learners to understand and perceive the displayed the invisible information. For example, in the medicine field, during the surgery, there is artificially displaying the information from the interior of the body on the appropriate. Another example of using augmented reality is displaying the main information on a screen in industrial and martial devices. Augmented reality is also used in tourism, advertising, and in a mobile phone. In a mobile phone, this application can determine the location of the user, introduce for the user information about the nearest street with all places and landmarks [24].

\section{E. Designing}

Designing using VR is not limited to a specific field. VR can be used to design the driving simulator, copying, and simulation of famous buildings that users can walk through a virtual historical building, in gaming and allow the user to interact with other users and exchange displays information with others [24].

\section{F. Construction progress monitoring}

Construction progress monitoring has been recognized as one of the key elements that lead to the success of a construction project. On the other word, by performing advanced control, exact measurement and other suitable procedures and steps can be fulfilled in the specific time [25]. Accordingly, it will certainly be easy to enable the performance to be as close as possible to the desired outcome even if the structure performance significantly deviates from the main design. Nevertheless, the ways of data acquisition nowadays and its use in construction progress monitoring has tended to be manual and time-consuming. The complicated nature of construction works makes the detailed progress monitoring challenging. Current construction progress monitoring methods involve submission of periodic reports and compelled by their dependence on manually dense processes and limited support for recording visual information [26]. Recently, the techniques of image based visualization allow using reporting construction progress by using "interactive and visual approaches" [27].
The virtual models can be useful both in face-to-face classes and in distance learning using E-learning technology. VR technique can easily provide chances to transfer technical education in ways not possible through traditional methods, thereby expanded the range of tools available to students to allow more educators and subjects are getting benefits. On the other hand, Birzina et al. [28] argued that to make a didactic application be used as an E-learning tool, it should be reusable, accessible, durable and interoperable.

\section{THE VR REQUIREMENTS}

Based on the definitions mentioned above and after having a look at the history of VR technologies, we would like to indicate and understanding the requirement of VR. According to [29] who asked the following question "if one were to create a VR that behaves like our world, what would be the requirements?" The researcher answered saying that the "information processing constancy" should be supposed by one and it operates the same trend for word processing regarding information processing in our world involves discrete management, certain processes for arithmetic matters, limited memory treatment. Accordingly, VR processing assumed to work the same way. The research [29] also indicated to the following requirements that are:

\section{A. Finite processing allocations}

This requirement means that the processing creates the VR conducts as the real world around us allocates the processing in limited "finite" quantities. The finite processing allocations assumed that each amount of time, space, and power has a "finite information capacity."

Autonomy: Autonomy here means the VR assumed to conduct by itself as the real world behaves without external data and information input [29].

\section{B. Consistent self-registration}

This requirement means the VR conducts like the reality to register itself systematically to internal "observers." The reality registered when light from the world interacts with our eyes, also in the same world. For a VR to "register itself" as we do, internal interactions must be consistent on each local "observer [29]".

\section{Calculability}

Calculability requirement means the VR conducts like the real world that should calculate at all time. The source in the system of VR should enclose each calculation does finite and not tend to infinity. For example, "the processing demands of some many-body calculations explode to incalculability".

All these above requirements affect the system to be VR. The requirements are like constraints for making VR in the real world.

Another researcher [30] indicated in his research that the three primary requirements to develop the environment of the VR are:

1) Performance: The VR environment requires low latency with a high rate of the frame. It is inconvenient for the user if the performance of VR environments is poor. Then, the 
systems of VR have to get the benefits of available resources such as special graphics hardware and processors [30].

2) Flexibility: The devices and software used in development, VR environment should adjust with that devices and software configurations. That configuration has to be new [30].

3) Ease of use: The required VR environment to be developed has to be learned and configure easily by the user. "The Application Programming Interfaces (APIs) and languages used to create applications should be cleanly designed and should hide as much of the system's underlying complexity as possible" [30].

The interaction technique by the users of all three types of VR systems is one requirement of the user interface for the users of VR technologies. The requirements are input, output, and the interaction [24]. Interaction in VR systems is essential because it "outlines the mapping path between the user and the VR environment and determines how the environment will react when the user interacts using the input devices" [31]. The interaction technique gives the users the ability to navigate and travel in the virtual environment.

There are three types of interaction technique as it is tracking technique in VR systems. The types are navigation, object selection and manipulation, and system control (view control) [24], [32].

Navigation means choosing an orientation in space or place to determine the specific location of an object [33]. Navigation is tracking that allows users to move and travel inside virtual environments [24].

The navigation task of interaction furthermore divided into three main categories. The categories of navigation are exploration, searching, and maneuvering. Navigation with all its categories allows the user to locate the standpoint at more beneficial points to perform a particular task [31].

Object selection and manipulation enables the user to track a specific object in VR environment by using the hand of the user and to choose an object for manipulation. The user can perform the selection by gestures of hands, head orientation, eyes direction, or by using input devices such as mouse, keyboard, or joysticks [24], [32].

System control (view control) is called interactivity [34]. System control allows the user to communicate with a virtual environment (3D world) and allowing the communication among different users [24]. System control acts like a command performed to change the action of the system or the mode of interaction [31].

\section{ESSENTIAL ELEMENTS OF VR}

The system of VR essentially has four basic elements. These elements determined by researchers Sherman and Craig [35]. The elements are the following:
1) Virtual World: It is a world generated by a computer. The virtual world consists of objects and principles of space. Those objects and principles integrated with each other by relationships.

2) Immersion: It makes the sensibility of the world as the user lives inside it and can touch it. Immersion not being just seen the world without sense it.

3) Sensory feedback: This element allows the user to reach a sensible result based on what is the input by the user. The sensibility result also based on the user place, action, and navigation.

4) Interactivity: This fourth element is responsible for offering the realization and for representing the virtual world. It allows the user to interact with objects in virtual world place.

These four elements are the basic elements in the VR system by using a computer.

\section{TYPES OF VR SYSTEMS AND HARDWARE}

The different types of the VR systems are classified according to different usage of technological supply. Those various supplies and equipment are represented in various displayed hardware and interaction devices. "VR systems are classified according to the level of immersion they provide, ranging from semi-immersive (or desktop) VR to fully immersive VR to augmented reality (AR)" [31].

The different types of VR systems that use various technological devices and perform different functions are shown through the following explanation:

\section{A. Immersion Systems (Fully-immersive)}

The immersion type of VR systems requires the user to wear a data glove and HMD that tracks the user's head movements that then changes the view [22], [24]. CAVE is an example of fully immersion technology. CAVE designed and implemented to deal and treatment the challenges of creating a one-to-many visualization tool that utilizes large projection screens [32].

This type of VR system encases the audio and visual perception of the user in the virtual world and cuts out all outside information so that the experience is fully immersive. This type of technology is expensive and has some disadvantages, including less determining images, burden and environmental problems concerning simulators [31]. The user using full immersion of VR technology has the ability of feeling of being part of the virtual environment. An example of using this type of VR is in a virtual walk-through of buildings as one application of full immersion [8].

The examples of using full immersion of VR are shown in Fig. 10. It represents the "Light Vehicle Simulator" of fully immersed used for training purposes. This type of simulator allows users to learn how to deal with and respond to emergencies and risks when the user is driving the vehicles on mine sites [32]. 


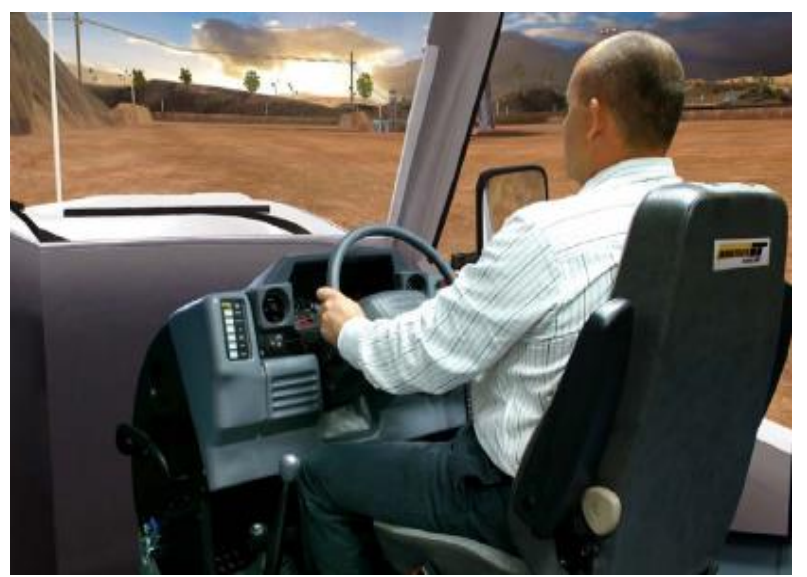

Fig. 10. Example of using the light vehicle simulator in full immersion VR.

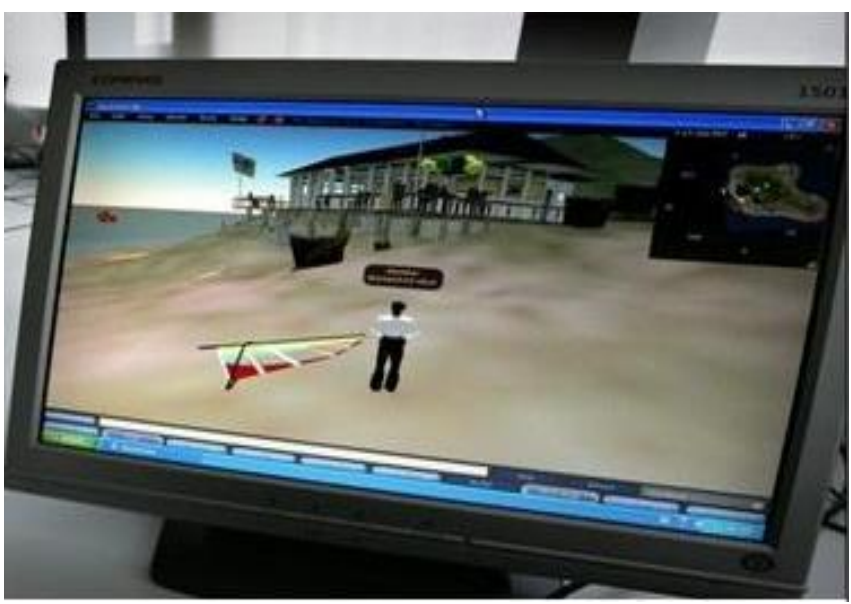

Fig. 11. An example of using only a computer in desktop VR system.

\section{B. Non-Immersive system}

The non-immersive system is often called desktop virtual reality (without any input devices) and based on the displayed screens as it is a window to the virtual world without additional devices such as HMD, and it is sometimes called Window on World (WoW) systems [3], [36]. The most widely used VR system is the desktop system that consists of a standard computer monitor to display the virtual world. Although these systems provide a lower level of presence and perhaps interaction, they can achieve satisfactory levels of graphic quality, user comfort and convenience and lower costs [22], [34].

The desktop VR system is the least types of immersion and lowest cost of the VR systems. Non-immersive type of VR is the least sophisticated components and mostly used in education [8].

Examples of desktop VR systems are video games and other examples represented in Fig. 11. It shows the nonimmersion system based on the screen that contains only $3 \mathrm{D}$ display without any interaction. It combines VR with realworld attributes by integrating computer graphic objects into a real-world scene, but without interacting with objects that in screen [31].
Another form of desktop VR system is a virtual world. It used in education to support the learning and enhance the user to understand and observe the information. Pull together systems of the virtual world provides interactions among humans through many avatars [31]. Many of open-source software packages such as "Second Life, Active World, Open Simulator, and Open Croquet" are available to construct virtual worlds [37].

\section{Semi-Immersive system}

The third type of VR systems also called hybrid systems. The semi-immersive is a development desktop VR and include additional devices such as Data Gloves. It keeps the simplicity of the desktop VR system, but with a high level of immersion and using physical models [8]. In semi-immersive, the displayed virtual environment is set up onto the recognized real environment [24]. For building semi-immersive system, the requirement is displaying, tracking sensors, and user interfaces [32].

The semi-immersive system consists of VR and real world attributes by embodying objects of computer graphic into the scene of the reality. The input to this type of system is entered and controlled by the users such as a mouse, keyboard, interaction styles, glasses, and joystick [31]. It allows the user to interact by using the hands and sometimes wear glasses or DataGloves.

The displayed information such as text, graphs, and images are jutting onto the transparent screen to allow the user to interact with the real environment. An example of using hybrid systems is shown in Fig. 12. Fig. 13 represents example for semi-immersive systems [38], [39].

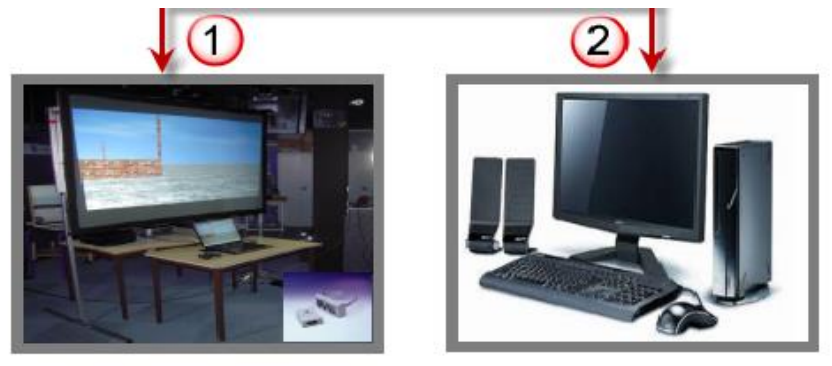

Fig. 12. Example of semi-immersive, (1) projection screen, laptop, and Iglasses; (2) conventional monitor, keyboard, and mouse, [31].

The following Table 1 displayed the main differences among the three types of immersion VR system:

TABLE. I. COMPARISONS AMONG THE THREE TYPES OF VR SYSTEMS

\begin{tabular}{|l|c|c|c|}
\hline & $\begin{array}{c}\text { Fully- } \\
\text { immersive }\end{array}$ & Semi-Immersive & Non-immersive \\
\hline Resolution & High & High & $\begin{array}{c}\text { Medium - } \\
\text { Low }\end{array}$ \\
\hline $\begin{array}{l}\text { Sense of } \\
\text { mersion }\end{array}$ & Low-Non & $\begin{array}{c}\text { Medium - } \\
\text { High }\end{array}$ & Low \\
\hline Interaction & Low & Medium & High \\
\hline Price & Lowest cost & $\begin{array}{c}\text { Relatively } \\
\text { Expensive }\end{array}$ & $\begin{array}{c}\text { Very } \\
\text { Expensive }\end{array}$ \\
\hline
\end{tabular}


TABLE. II. CATEGORIES OF VR SOFTWARE ACCORDING TO ITS FinANCIAL VALUE

\begin{tabular}{|c|c|c|c|}
\hline Free of Charge Software & Inexpensive Software & Moderately Expensive Software & Expensive Software \\
\hline $\begin{array}{l}\text { Software products that are free } \\
\text { (commonly referred to as } \\
\text { freeware or shareware) are } \\
\text { copyrighted, and commercial use } \\
\text { is often restricted. Examples } \\
\text { include Alice, DIVE, and the } \\
\text { common VR Modeling Language } \\
\text { (VRML). }\end{array}$ & $\begin{array}{l}\text { Computer games are classified within } \\
\text { the commercial VR programs. This type } \\
\text { of programs is currently at the forefront } \\
\text { of VR technology. The games can } \\
\text { feature realistic graphics and sound, } \\
\text { interaction, are distributed cheaply and } \\
\text { are used by millions of people. 3D } \\
\text { editors are also available which allow } \\
\text { players to modify and even create their } \\
\text { own 3D worlds for these game } \\
\text { environments. }\end{array}$ & $\begin{array}{l}\text { The software in this category does } \\
\text { not require any expert hardware } \\
\text { beyond the basic computer system. It } \\
\text { has many of excellent professional } \\
\text { packages, three of which are World } \\
\text { Tool Kit, which is a toolkit } \\
\text { consisting of a library of } \\
\text { programming functions, VR Toolkit } \\
\text { which is an authoring package and } \\
\text { Macromedia Director Shockwave } \\
\text { Studio. }\end{array}$ & $\begin{array}{l}\text { The VR software packages in this } \\
\text { category are typically aimed at the } \\
\text { professional market and can often } \\
\text { require high computer specifications; } \\
\text { these are known as a workstation or } \\
\text { Rackable Systems Inc, which } \\
\text { nowadays is known as Silicon } \\
\text { Graphics International (SGI) system. } \\
\text { These categories often demand much } \\
\text { expensive hardware, such as that } \\
\text { used in flight simulators. }\end{array}$ \\
\hline
\end{tabular}

\section{VR SOFTWARE AND TOOLS}

According to increasing and using the VR technology in many fields around the world, the tools and software to develop and use VR systems are available and still growing. To realize the applications of VR systems, the software is the key factor to recognize those applications [23].

There are two main types of VR software available: toolkits and authoring systems. Some of the VR applications are the framework, while others are complete development environments [22], [40]. Every VR environment is created and constructed by many aspects (modeling, coding, and then executing) and these aspects should be integrated into a single package [30].

The first type includes special programs for library usage that allows a proficient programmer to create a VR application by introducing a set of functions (Toolkits). However, the authoring systems are a simple program created without having recourse to detailed programming, but with graphical interfaces. In Table 2, there are some VR toolkits and authoring software applications available as shown through the following points, ranging from software packages that are free to use for those that are expensive [22]:

The software of VR technology has four main components that are "3D modeling software, 2D graphics software, digital sound editing software and VR simulation software" according to Onyesolu [40].

\section{A. $3 D$ modeling software}

It is a program used to inspire 3D images using a computer and then build geometry objects in VR environments. Examples of tools used in this component of software are:

1) Autodesk 3d Max: It has another name that is 3D Studio MAX. It is extensive with many sides 3D application used in film, TV, video games and architecture. It works with Windows and Apple Macintosh operating system.

2) GL Studio: It makes interactive 3D graphics with the user interface. GL Studio based on a programming language that is $\mathrm{C}++$ and OpenGL source code to create virtual worlds with interfaces.

3) Electric Image Animation System (EIAS): Creates animated 3D environments. Mostly it used to generate films such as Hollywood that used it extensively.

4) Maya: Maya software is used in to create the movie, and on TV, and to create gaming industry with the 3D virtual world. It is compatible with many operating systems Windows, Linux, and Mac. Many other examples such are Massive, Cobalt, Cinema 4D, and AC3D. It can call either 2D graphics editor or drawing program. It used to play and operate objects in $3 \mathrm{D}$ constructions to support the visual details.

\section{B. 2 D graphics software}

The 2D graphics software creates images, diagrams and manipulates it by using the mouse, graphics tablet, or similar hardware.

This type of $2 \mathrm{D}$ software is also used in drawings such as electrical, electronic diagrams, topographic maps, and fonts in a computer. It is a program used to integrate the components of VR and how its objects conduct and set the rules to guide VR environment to follow it.

\section{VR simulation software}

An example of this simulation software is OpenSimulator (OpenSim). It is a 3D application server to create a 3D environment; it has many tools for developers to improve and build various applications such as chat application among avatars. OpenSim supports many programming languages such as Linden Scripting Language, C\#, and JScript and VB.NET to develop the application.

Another example of VR simulation is Ogoglio. It is an open source 3D graphical stage used to build online spaces for artistic collaboration. It is considered as scripting language similar to Javascript. It is compatible with Windows, Linux, Solaris operating system and can run on any browser.

Another example is Flexsim DS. It is considered the advanced 3D simulation recently. FlexSim DS used to build distributed VR environments through networks.

\section{Digital sound editing software}

This type of editing software is used to edit and mix sounds in VR environments with other objects available in the same environment. Examples of sound editing software are Audiobook Cutter Free Edition, Creative Wavestudio, FlexiMusic Wave Editor, Goldwave, Media Digitalizer, and mp3DirectCut. VR environments can be constructed and build $3 \mathrm{D}$ objects with animation and user interfaces with integrated a programming language with the language of VR that is VR Modelling Language (VRML) [41]. VRML is a modeling language written easily to represent Scalable Vector Graphics (SVG). VRML can be used alone and viewed on a player or a viewer or onto a Web browser with an additional plug-in to run 
it [42]. Most of the 3D environments and the interactive virtual world constructed and created by using VRML language that has improved through different versions since its inception in 1994 [43].

Nowadays, VRML became one of the most common 3D languages and filed to construct VR. VRML mostly used according to feature that it can easily access data structure essentially. VRML files can be downloaded and executed on a computer independently. However, it needs an additional plugin to run and operate on any player or viewer [34].

\section{NAVIGATION IN VR ENVIRONMENT}

The VR consists of 3D objects as any another animated 3D image. There are three components which distinguish between the VR and other 3D objects and multimedia such as television and multimedia. Three main components to make VR are: navigation, immersion, and interaction [31], [44].

1) Navigation: It is the essential tool for the usability in the VR. It is the main part to form virtual environments [45]. The navigation task allows the user to move from one place to another one in the VR. It provides the user the guidance about the destination and place of 3D objects [46], [44].

2) Immersion: It allows the user the feel of sense and presence as in the real world. The feeling of immersion could bring by the $3 \mathrm{D}$ objects, by the interaction with it, and by the navigation through the VR environment.

3) Interaction: It is done between the user and the objects in the virtual world to give the user the feeling of presence and the feel of acting within the reality environment in real time [31].

In the VR, the main component which leads to the other components is the navigation. The navigation behaviors in VR allow the user to interact and manipulate the $3 \mathrm{D}$ objects by input/output devices. The devices in a semi-immersive (developed desktop VR) are like mouse, keyboard, 3D mouse, and joystick. These allow the navigation in VR to improve the spatial presence (cognitive map) of the user [47], [48].

The cognitive map means the mental images. The first term of the cognitive map used by Tolman to mean the cognitive map is the description of the mental representation of spatial information and it is the internal (mentally) representation of spatial environments [49]. The cognitive map used to solve the spatial problems (visualization) such that we need in our research by the navigation as many types of research conclude it [50], [51].

The interaction in VR has three types of tasks. The tasks are navigation, manipulation (selecting), and system control [31]. The navigation task as we know is moving from one point to another among 3D objects in VR. It allows the movement between many different locations in the virtual world. The navigation task consists of two components that are [52], [53], [31]:
1) Travel (the motor component): means the movement from one particular location in virtual space to another one.

2) Wayfinding (the cognitive component): means the process of connection to find the paths in VR to travel through it. The wayfinding and travel build up and improve the cognitive map (spatial visualization).

Moreover, the navigation task classified into three categories that are maneuvering, search tasks and exploration allows the user to navigate (move) and travel from one viewpoint in VR to another point of view.

The manipulation (selecting) is selecting a specific object in VR and by choosing the user can start the manipulations such as rotate, zoom in, zoom out, and flying over the objects. Selecting allows the user to apply a specific command for the selected object and to change the attributes of the selected object. The third component is system control. It is the changing of the state of a system or mode of interaction [31], [44].

The navigation, cognitive map, and wayfinding have a relationship with each other. The navigation and wayfinding improve the cognitive map (spatial skill) to solve the spatial problems. The navigation and wayfinding are terms used interchangeably to refer to "a person's abilities, both cognitive and behavioral, to reach spatial destinations" [54].

The wayfinding is one component of the navigation task. Wayfinding does not mean the travel over the objects, but it means the tactical part of manipulation to allow the user of VR to apply the third part of VR environment in our model which we will build the system according to the framework of cognitive theory by Daghestani. The motion refers to the term of travel that allows users to move the objects in the virtual world [55]-[57].

So, the cognitive map by navigation and wayfinding helps to improve the visualization ability and skill in the VR to visualize the paths, locations, detail of objects and its features. The cognitive map allows the person to remember and visualize the structure of objects and its locations in the VR [54]. The navigation is the result of exploration, manipulation and searching in the virtual environments. According to the navigation, the spatial awareness (spatial visualization) is improved [58].

The navigation in VR and specifically in desktop VR (semi-immersive) can be done by the six degrees of freedom (6DoF). The navigation with $6 \mathrm{DoF}$ as shown in Fig. 13 support the spatial reasoning by allowing students to manipulate a model to examine its parts, scan its features, display many objects that make one solid model and compare these objects, define the spatial styling of an object [38].

The six DOF means can see the object from six sides that are: up-down; left-right; forward-back; pitch; yaw; and roll, and allow users to navigate and manipulate the objects in the VR environments. 


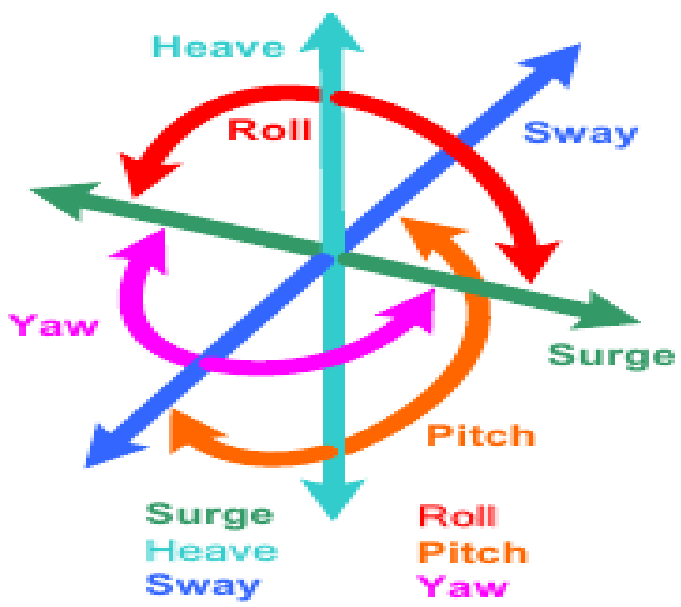

Fig. 13. Six degrees of freedom.

\section{BENEFITS AND LiMITATION OF VR}

Among the prominent advantages and benefits of VR, as it can help to change the circumstances surrounded the users or trainers to make them live in the actual situations saving both time and cost. In other words, VR can help to allow users in viewing world that is modeled inside computers and enable them to test and try things that are not normally accessible in our world or not yet formed [59].

The main advantages of VR could be as the following [32], [21], [22], [60]-[62]:

1) Any systems in technique could have many features that are either too small or large. The VR allow the user to monitor, control, and observe that feature in the normal scale system.

2) VR allows the user to feel and sense the "non-real time." Non- real time means a case or situation either offered in fast time or slow.

3) VR is safe more than the real world. So, it is used to enhance the education, training tools and experience. VR introduces the students with realism and interactivity.

4) Simulate the interaction and its speed or faster that in the real world.

5) Most of the systems in VR give the users opportunities to repeat the task until the user fulfills that task professionally with desired skills.

6) The virtual environment is much safer than the real environments.

7) VR technology gives the users of VR the ability of observations and monitoring from many numbers of views.

8) VR technology support and enhance the distance learning and avoid real danger, break the limitations of time, provides a riches of educational resources for students to allow them to explore learning independently. It enhances the selflearning.

9) VR is the most technology used to improve the engineering training, architected, and in the company of road and street, not only in engineering but also in medicine and education environments as we see in VR applications.
10) VR does not require users to present in the same place of training any system simulation that the user can train even if he/she is in another country.

11)By using $3 \mathrm{D}$ simulation in VR technology, the cultural information could be presented in 3D models from many angles. It allows people to sense and understand social science, landscape, and traditions of the real world.

Those advantages are not only the benefits of VR technology, but it could be the main characteristics of VR. The advantages of VR could not be counted so that the above features could be as many examples of its benefits.

However, there is no doubt that VR has been facing some noticeable, limitations and obstacles. As VR allows users to interact in real-time, this benefit needs a computer process to manipulate the virtual world with real-time as in reality. "The changes made on the virtual prototype will have to be reflected in real time; otherwise the best visual effects produced by this technology will be completely lost" [63].

Some types of VR system require much more money to create it such as in full-immersion system. Moreover, the VR technology should be improved and developed permanently as the world and techniques are increasing and improving.

\section{ROAD OF THE MAP FOR SElECtING APPROPRIATE VR SYSTEM ACCORDING TO THE FIELD OF APPLICATIONS}

The features and drawback of each type of VR system depends on what application is used. Some application is extremely useful if it is implemented using fully, while it has not benefitted if it is implemented using non-immersive.

To clarify what we mean, we make a table for the applications with all three systems to show when the system is good or low to use the application. Table 3 illustrates the type of systems and whether it is appropriate or inappropriate according to the application used.

\section{CONCLUSION AND FUTURE WORKS}

The importance of using the VR came according to the increasing demand for the invention with the correct perception of what studied in higher education for many majors. Some of these majors are math, computer science, medicine, and for sure in engineering.

The VR technology is introduced as an educational environment as innovation tool to enhance learners to be able to increase and improve the value of their solutions for solving the problem in complex life. The complex problem can be broken into small problems by breaking the complex problem leads learners to produce a unique solution, realistic and practical [64].

In this paper, we illustrate the concepts of VR systems and applications. We represented the requirements and essential elements to build a complete VR environment. Benefits and limitation of $\mathrm{VR}$ are also introduced in this survey paper.

A road map for choosing appropriate VR system according to the required application is finally presented based on the discussed VR systems, applications, and tools. For the future work, we advise selecting a VR system based on many criteria 
such as price, the level of immersion, and goals of VR application.

For the future work, we will present another survey paper to compare among VR, AR, and Mixed Reality (MR) [8]. The MR combined both VR and AR. The MR keeps the feeling about the reality and generated virtual environment at the same time. An example of MR is Microsoft HoloLens. Moreover, it is proposed to use the MR in STEM fields which allows more interactions between the user and objects of the virtual environment.

TABLE. III. THE USING OF SYSTEM OF VR ACCORDING TO THE APPLICATIONS

\begin{tabular}{|c|c|c|c|}
\hline Field & Fully-immersive & Semi-immersive & Non-immersive \\
\hline Medicine & $\begin{array}{l}\text { Not effective to use fully-immersive in medicine } \\
\text { and will be very expensive }\end{array}$ & $\begin{array}{l}\text { Use it in making surgery; no harm will } \\
\text { come to animals or human being. } \\
\text { Not costly for each autopsy's } \\
\text { experiment } \\
\text { Can take the training many times by } \\
\text { using the system. However, it will not } \\
\text { be helpful if fully-immersive or non- } \\
\text { immersive }\end{array}$ & $\begin{array}{l}\text { It will not be useful if we use this system for } \\
\text { medicine }\end{array}$ \\
\hline $\begin{array}{l}\text { Education and } \\
\text { Training }\end{array}$ & $\begin{array}{l}\text { Fully-immersive is appropriate for training such as } \\
\text { driving, submarines, ships, cranes, and flight by } \\
\text { making flight simulator. It does not make useful } \\
\text { and leads to the goal for training if it used semi or } \\
\text { non-immersive. }\end{array}$ & $\begin{array}{l}\text { In education, such as engineering, } \\
\text { drawing, cooking, soon, the semi- } \\
\text { immersive is the most efficient system } \\
\text { for education. }\end{array}$ & $\begin{array}{l}\text { Non-immersive system such as AR is good } \\
\text { to show animated images, or convert images } \\
\text { to video from capture the page of a lesson in } \\
\text { education. }\end{array}$ \\
\hline $\begin{array}{l}\text { Entertainment } \\
\text { and Sport }\end{array}$ & $\begin{array}{l}\text { Fully-immersive for specific entertainment will be } \\
\text { effective. Such as seeing the sea with the animal } \\
\text { inside it. Some games for companies to enjoy } \\
\text { people and tourists to see new places by using } \\
\text { CAVE. }\end{array}$ & For sports and 3d game (PlayStation) & $\begin{array}{l}\text { Non-immersive is appropriate for } \\
\text { entertainment such AR video game, TV } \\
\text { cartoons, and football. }\end{array}$ \\
\hline $\begin{array}{l}\text { Engineering and } \\
\text { Architecture }\end{array}$ & $\begin{array}{l}\text { Fully immersive using to see the way of specific } \\
\text { building to simulate it. }\end{array}$ & $\begin{array}{l}\text { For engineering, the semi-immersive } \\
\text { system is effective to visualize the } 3 \mathrm{D} \\
\text { objects. }\end{array}$ & $\begin{array}{l}\text { After designing the virtual buildings, using } \\
\text { non-immersive to show the rooms and } \\
\text { furniture to check the correctness of } \\
\text { conception. }\end{array}$ \\
\hline $\begin{array}{l}\text { Data } \\
\text { Visualization }\end{array}$ & $\begin{array}{l}\text { There will no benefits if using fully-immersive for } \\
\text { data visualization such as the direction of rains; } \\
\text { Color represents temperature and direction } \\
\text { represent the direction of air flow and clouds. }\end{array}$ & $\begin{array}{l}\text { Mostly there is no need for interacting } \\
\text { with data visualization because we use } \\
\text { the VR for monitoring in data } \\
\text { visualization. }\end{array}$ & $\begin{array}{l}\text { Data visualization is the use of graphical } \\
\text { representations of information to make } \\
\text { certain characteristics or values more } \\
\text { apparent. } \\
\text { Use non-system in mapping geometric } \\
\text { objects, such as arrows or particle clouds, to } \\
\text { the data values. }\end{array}$ \\
\hline $\begin{array}{l}\text { Augmented } \\
\text { Reality }\end{array}$ & $\begin{array}{l}\text { AR specifically used for the non-immersive } \\
\text { system. }\end{array}$ & $\begin{array}{l}\text { AR specifically utilized for the non- } \\
\text { immersive system. }\end{array}$ & $\begin{array}{l}\text { AR used for non-immersive. For example, } \\
\text { in the medicine field, during the surgery, } \\
\text { there is artificially displaying the } \\
\text { information from the interior of the body at } \\
\text { the appropriate. Another example of using } \\
\text { AR is displaying the main information on a } \\
\text { screen in industrial and martial devices. AR } \\
\text { also used in tourism, advertising, and in a } \\
\text { mobile phone. }\end{array}$ \\
\hline Designing & $\begin{array}{l}\text { Fully-immersive VR can be used to design the } \\
\text { driving simulator, copying, and simulation of } \\
\text { famous buildings that users can walk through a } \\
\text { virtual historical building. }\end{array}$ & $\begin{array}{l}\text { Designing of 3D objects in } \\
\text { (engineering) will be affected if the } \\
\text { semi-immersive system uses it. }\end{array}$ & $\begin{array}{l}\text { Show 3D models for the others. 3D design } \\
\text { allows users to interact with other users and } \\
\text { exchange displays information with others }\end{array}$ \\
\hline $\begin{array}{l}\text { Construction } \\
\text { progress } \\
\text { monitoring }\end{array}$ & $\begin{array}{l}\text { Monitoring not within the system, but monitoring } \\
\text { by being far, no in the place and obtain more time. } \\
\text { Therefore, it effective by monitoring the progress } \\
\text { of data or working during the desktop VR. }\end{array}$ & $\begin{array}{l}\text { The techniques of image-based } \\
\text { visualization allow using reporting } \\
\text { construction progress by using } \\
\text { "interactive and visual approaches "such } \\
\text { as (monitoring the traffics inroads) and } \\
\text { to go to another road or place by } \\
\text { clicking and interacting with the desktop } \\
\text { display. }\end{array}$ & $\begin{array}{l}\text { Non-immersive with Construction progress } \\
\text { monitoring enable the performance to be as } \\
\text { close as possible to the wanted outcome } \\
\text { even if the construction performance } \\
\text { significantly deviates from the main design. }\end{array}$ \\
\hline
\end{tabular}




\section{REFERENCES}

[1] S. Jayaram, H. I. Connacher, and K. W. Lyons, "Virtual assembly using VR techniques," Computer-Aided Design, vol. 29, no. 8, pp. 575-584, 1997.

[2] S. Borsci, G. Lawson, and S. Broome, "Empirical evidence, evaluation criteria and challenges for the effectiveness of virtual and mixed reality tools for training operators of car service maintenance," Computers in Industry, vol. 67, pp. 17-26, 2015.

[3] S. Mandal, "Brief Introduction of VR \& its Challenges," 2013.

[4] J. C. Roberts, "On encouraging multiple views for visualization," in Information Visualization, 1998. Proceedings. 1998 IEEE Conference on, 1998, pp. 8-14.

[5] L. Rapanotti and J. G. Hall, "Design concerns in the engineering of virtual worlds for learning," Behaviour \& Information Technology, vol. 30, no. 1, pp. 27-37, 2011.

[6] J. T. Bell and H. S. Fogler, "The investigation and application of VR as an educational tool," in Proceedings of the American Society for Engineering Education, 1995.

[7] A. Rodriguez, B. Rey, M. Clemente, M. Wrzesien, and M. Alcañiz, "Assessing brain activations associated with emotional regulation during VR mood induction procedures," Expert Systems with Applications, vol. 42, no. 3, pp. 1699-1709, 2015.

[8] O. Bamodu and X. M. Ye, "VR and VR System Components," Advanced Materials Research, vol. 765, pp. 1169-1172, 2013.

[9] J. Fox, D. Arena, and J. N. Bailenson, "VR: a survival guide for the social scientist," Journal of Media Psychology, vol. 21, no. 3, pp. 95113, 2009.

[10] J. Novak-Marcincin, M. Kuzmiakova, and K. Al Beloushy, "VR TECHNOLOGIES AND VIRTUAL MANUFACTURING IN MANUFACTURING ENGINEERING.," Scientific Bulletin Series C: Fascicle Mechanics, Tribology, Machine Manufacturing Technology, vol. 23, no. 100, 2009.

[11] T. Mazuryk and M. Gervautz, "VR-history, applications, technology and future," 1996.

[12] J. Sharpe and R. Self, "Computers for Everyone," Computers for Everyone, vol. 1, no. 1, 2015.

[13] O. Bimber and R. Raskar, Spatial augmented reality: merging real and virtual worlds. CRC Press, 2005

[14] F. Rebelo, E. Duarte, P. Noriega, and M. M. Soares, "24 VR in Consumer," Human Factors and Ergonomics in Consumer Product Design: Methods and Techniques, p. 381, 2011.

[15] J. W. V. De Faria, E. G. Figueiredo, and M. J. Teixeira, "History of VR and its use in medicine," Revista de Medicina, vol. 93, no. 3, pp. 106114, 2015.

[16] G. Welch, "VR History ." 2015.

[17] M. Vafadar, "VR: Opportunities and Challenges," History of VR and its use in medicine, 2013.

[18] P. L. Weiss, H. Sveistrup, D. Rand, and R. Kizony, "Video capture VR: A decade of rehabilitation assessment and intervention," Physical Therapy Reviews, vol. 14, no. 5, pp. 307-321, 2009.

[19] S. S. Fisher, M. McGreevy, J. Humphries, and W. Robinett, "Virtual environment display system," in Proceedings of the 1986 workshop on Interactive 3D graphics, pp. 77-87, 1987.

[20] Z. Zivkovic, "Optical-flow-driven gadgets for gaming user interface," in Entertainment Computing-ICEC 2004, Springer, pp. 90-100, 2004.

[21] R. Hui-Zhen and L. Zong-Fa, "Application and Prospect of the VR Technology in College Ideological Education," in Intelligent Systems Design and Engineering Applications, 2013 Fourth International Conference on, pp. 125-128, 2013.

[22] C. Cox, "The use of computer graphics and VR for visual impact assessments," 2003.

[23] W. Jin, "VR technology in the design of the space environment research," in Control, Automation and Systems Engineering (CASE), 2011 International Conference on, 2011, pp. 1-4.

[24] M. Mihelj, D. Novak, and S. Beguvs, VR Technology and Applications. Springer, 2014.
[25] H. Son and C. Kim, "3D structural component recognition and modeling method using color and 3D data for construction progress monitoring," Automation in Construction, vol. 19, no. 7, pp. 844-854, 2010.

[26] S. Roh, Z. Aziz, and F. Peña-Mora, "An object-based 3D walk-through model for interior construction progress monitoring," Automation in Construction, vol. 20, no. 1, pp. 66-75, 2011.

[27] A. Z. Sampaio, "VR Technology Applied in Teaching and Research in Civil Engineering Education."

[28] R. Birzina, A. Fernate, I. Luka, I. Maslo, and S. Surikova, "E-learning as a Challenge for Widening of Opportunities for Improvement of Students' Generic Competences," E-Learning and Digital Media, vol. 9, no. 2, pp. 130-142, 2012.

[29] B. Whitworth, "The physical world as a VR," arXiv preprint arXiv:0801.0337, 2008.

[30] A. Bierbaum and C. Just, "Software tools for VR application development," Course Notes for SIGGRAPH, vol. 98, 1998.

[31] L. Daghestani, “The Design, Implementation and Evaluation of a Desktop VR for Teaching Numeracy Concepts via Virtual Manipulatives," 2013.

[32] M. A. Muhanna, "VR and the CAVE: Taxonomy, interaction challenges and research directions," Journal of King Saud University-Computer and Information Sciences, 2015.

[33] T. Sulbaran and N. C. Baker, "Enhancing engineering education through distributed VR," in Frontiers in Education Conference, 2000. FIE 2000. 30th Annual, vol. 2, p. S1D-13, 2000.

[34] W. Cartwright and M. P. Peterson, Multimedia cartography. Springer, 2007.

[35] P. Brey, "VR and computer simulation," The Handbook of Information and Computer Ethics, p. 361, 2008.

[36] N. Sala, "Multimedia and VR in architecture and in engineering education," in Proceedings of the 2nd WSEAS/IASME International Conference on Educational Technologies, Bucharest, Romania, vol. 22, 2006.

[37] J. Kaplan and N. Yankelovich, “Open Wonderland: an extensible virtual world architecture," Internet Computing, IEEE, vol. 15, no. 5, pp. 3845,2011

[38] S. Sua, A. Chaudhary, B. Geveci, W. Sherman, H. Nieto, L. FranciscoRevilla, and others, "VR enabled scientific visualization workflow," in Everyday VR (WEVR), 2015 IEEE 1st Workshop on, pp. 29-32, 2015.

[39] E. T. Solovey, J. Okerlund, C. Hoef, J. Davis, and O. Shaer, "Augmenting spatial skills with semi-immersive interactive desktop displays: do immersion cues matter?," in Proceedings of the 6th Augmented Human International Conference, pp. 53-60, 2015.

[40] M. O. Onyesolu, I. Ezeani, and O. R. Okonkwo, A Survey of Some VR Tools and Resources. INTECH Open Access Publisher, 2012.

[41] X. Fang, D. Zheng, H. He, and Z. Ni, "Data-driven heuristic dynamic programming with VR," Neurocomputing, 2015.

[42] F. Ziwar and R. Elias, "VRML to WebGL Web-based converter application," in Engineering and Technology (ICET), International Conference on, 2014, pp. 1-6, 2014.

[43] J. Martin-Gutierrez, M. Garcia-Dominguez, C. Roca Gonzalez, and M. M. Corredeguas, "Using different methodologies and technologies to training spatial skill in Engineering Graphic subjects," in Frontiers in Education Conference, 2013 IEEE, pp. 362-368, 2013.

[44] J. ao A. onio M. P. Joaquim Armando Pires Jorge, "Direct Interactive 3D Modeling in a Semi-Immersive Environment," 2013.

[45] G. Opriessnig, "User-defined mapping functions and collision detection to improve the user-friendliness of navigation in a VR environment," in Information Visualization, 2003. IV 2003. Proceedings. Seventh International Conference on, pp. 446-451, 2003.

[46] J. Ma, H. Zhu, and J. Gong, "Study of navigation based on intelligent avatar with mobile VR," in Wireless, Mobile and Multimedia Networks, 2006 IET International Conference on, pp. 1-4, 2006.

[47] T. D. Parsons, C. G. Courtney, M. E. Dawson, A. A. Rizzo, and B. J. Arizmendi, "Visuospatial processing and learning effects in VR based mental rotation and navigational tasks," in Engineering Psychology and 
Cognitive Ergonomics. Understanding Human Cognition, Springer, pp. $75-83,2013$

[48] M. Muhaiyuddin, N. Diyana, and D. R. Awang Rambli, "Navigation in image-based VR as the factor to elicit spatial presence experience," in Technology Management and Emerging Technologies (ISTMET), 2014 International Symposium on, pp. 349-354, 2014.

[49] S. K. Semwal, "Wayfinding and navigation in haptic virtual environments," in null, p. 143, 2001.

[50] P. Hafner, C. Vinke, V. Hafner, J. Ovtcharova, and W. Schotte, "The impact of motion in virtual environments on memorization performance," in Computational Intelligence and Virtual Environments for Measurement Systems and Applications (CIVEMSA), 2013 IEEE International Conference on, pp. 104-109, 2013.

[51] G. Wallet, H. Sauzéon, F. Larrue, and B. N'Kaoua, "Virtual/real transfer in a large-scale environment: impact of active navigation as a function of the viewpoint displacement effect and recall tasks," Advances in Human-Computer Interaction, vol. 2013, p. 8, 2013.

[52] B. S. Santos, P. Dias, A. Pimentel, J.-W. Baggerman, C. Ferreira, S. Silva, and J. Madeira, "Head-mounted display versus desktop for 3D navigation in VR: a user study," Multimedia Tools and Applications, vol. 41, no. 1, pp. 161-181, 2009.

[53] E. Suma, S. L. Finkelstein, M. Reid, S. V. Babu, A. C. Ulinski, L. F. Hodges, and others, "Evaluation of the cognitive effects of travel technique in complex real and virtual environments," Visualization and Computer Graphics, IEEE Transactions on, 2010.

[54] K. Patel and S. Vij, "Spatial navigation in virtual world," Advanced knowledge based systems: model, applications and research, TMRF eBook, pp. 101-125, 2010.
[55] D. A. Bowman and L. F. Hodges, "An evaluation of techniques for grabbing and manipulating remote objects in immersive virtual environments," in Proceedings of the 1997 symposium on Interactive 3D graphics, 1997.

[56] N. G. Vinson, "Design guidelines for landmarks to support navigation in virtual environments," in Proceedings of the SIGCHI conference on Human Factors in Computing Systems, 1999.

[57] C.-H. Tang, W.-T. Wu, and C.-Y. Lin, "Using VR to determine how emergency signs facilitate way-finding," Applied ergonomics, vol. 40, no. 4, pp. 722-730, 2009.

[58] G. A. Satalich, "Navigation and wayfinding in VR: Finding the proper tools and cues to enhance navigational awareness," 1995.

[59] M. J. Williams, "Application of VR for risk assessment and training in the minerals industry," 2000.

[60] A.-H. G. Abulrub, A. N. Attridge, M. Williams, and others, "VR in engineering education: The future of creative learning," in Global Engineering Education Conference (EDUCON), IEEE, 2011.

[61] H. Chen, K. Feng, C. Mo, S. Cheng, Z. Guo, and Y. Huang, "Application of Augmented Reality in Engineering Graphics Education," in IT in Medicine and Education (ITME), 2011 International Symposium on, vol. 2, pp. 362-365, 2011.

[62] G. Li and B. Zhang, "The application and advantages of VR technology in cultural resources communication," in 2011 International Conference on Multimedia Technology, 2011.

[63] A. Jimeno and A. Puerta, "State of the art of the VR applied to design and manufacturing processes," The International Journal of Advanced Manufacturing Technology, vol. 33, no. 9, pp. 866-874, 2007.

[64] I. Kartiko, M. Kavakli, and K. Cheng, "Learning science in a VR application: The impacts of animated-virtual actors' visual complexity," Computers \& Education, vol. 55, no. 2, pp. 881-891, 2010. 